\begin{tabular}{l} 
RCCS \\
\hline Annual Review
\end{tabular}

\section{RCCS Annual Review}

A selection from the Portuguese journal Revista Crítica de Ciências Sociais

$1 \mid 2009$

Issue no. 1

\title{
The Art of Escape: Liquidity Mechanisms
}

José Maria Castro Caldas

Translator: Karen Bennett

\section{(2) OpenEdition}

Journals

Electronic version

URL: http://journals.openedition.org/rccsar/180

DOI: $10.4000 /$ rccsar. 180

ISSN: $1647-3175$

Publisher

Centro de Estudos Sociais da Universidade de Coimbra

\section{ELECTRONIC REFERENCE}

José Maria Castro Caldas, « The Art of Escape: Liquidity Mechanisms », RCCS Annual Review [Online], 1 | 2009, Online since 01 September 2009, connection on 01 May 2019. URL : http://journals.openedition.org/rccsar/180 ; DOI : 10.4000/rccsar.180 


\section{José Maria Castro Caldas}

Centre for Social Studies, University of Coimbra, Portugal

\section{The Art of Escape: Liquidity Mechanisms*}

The idea of "liquidity" as a characteristic of the present phase of modernity, which features in the most recent work of Zygmunt Bauman, invites comparison with Keynes. In both Bauman and Keynes, liquidity is applied to relationships that are easily revertible (or revertible at low cost) and to systems that are unstable and precarious due to the precariousness of the bonds that unite their constituent elements. In both authors, liquidity and speculation appear as rational responses to uncertainty and, at the same time, as individual strategies that contribute to increased risk at the level of the system. The two approaches are complementary and coherent. This comparative reading suggests the existence of transversal liquidity mechanisms that cut across different institutional domains, as described in this paper.

Keywords: Liquid modernity; liquidity mechanisms; uncertainty; Bauman; Keynes.

\section{Introduction}

The presence of the Keynesian word "liquidity" in the title of Zygmunt Bauman's book Liquid Modernity is more than mere coincidence. In Bauman, liquidity is invoked in order to explain a society which, due to its weak resistance "against the separation of the atoms" (Bauman, 2000: 2), has difficulty keeping its shape. In Keynes, it refers to a property of the financial markets - the ease with which agents may divest themselves of their assets and acquire others with which to replace them. Nonetheless, in both Bauman and Keynes, liquidity is applied to relationships that are easily revertible, or revertible at low cost, and to systems that are unstable and precarious due to the precariousness of the bonds that unite their constituent elements. For both, liquidity is a fitting metaphor "when we wish to grasp the nature of the present, in many ways novel, phase, in the history of modernity" (Bauman, 2000: 2).

At first sight, the parallelism does not take us much beyond these observations. The two analyses are situated on different planes. While Bauman is concerned with different manifestations of "the separation of the atoms," taking as reference the totality of social and existential experience, Keynes, more modestly, deals with individual strategies and their

\footnotetext{
* Article published in RCCS 82 (September 2008). The author would like to thank José Reis, João Rodrigues, Luís Francisco Carvalho, Ana Santos and Margarida Moz, for their careful reading, critical comments and corrections of an earlier version of this article.
} 
systemic consequences within the more precise institutional domain of the monetary and financial markets.

However, as it happens, the two approaches are complementary and coherent. The liquidity of the financial markets analysed by Keynes is a manifestation of a generalised process in a particular domain which, for Bauman (2000: 121), is the "paramount source of uncertainty" and the origin of processes which tend to extend and become widespread. Moreover, the comparison suggests that liquidity is manifested in a similar way in different spaces of social and personal life - a similarity that suggests the existence of transversal liquidity mechanisms.

In this paper, I shall not undertake a critical reading of Bauman and Keynes, but rather a joint interpretation of both, oriented towards an examination of hypothetical liquidity mechanisms operating transversally across different institutional domains. In the pages that follow, I shall first present the theses of Bauman and Keynes, or at least interpretations of them that have arisen from the comparative reading. These interpretations will support my identification of the various liquidity mechanisms described in Section 4. The discussion of trends arising from these hypothetically described mechanisms is left to the concluding notes.

\section{Bauman's liquidity}

Liquidity, as a metaphor for commercial society, was not invented by Bauman. He himself recognises this fact when alluding to the "melting of solids" in the Communist Manifesto. It is relevant to recall here that, in the Manifesto, the "melting of solids" concerned the "pitiless" tearing asunder by the bourgeoisie "of all feudal, patriarchal, idyllic relations," which left "no other nexus between man and man than naked self-interest, than callous 'cash payment'" (Marx \& Engels, 1848: 9). The reference to Thomas Carlyle and his "cash nexus" shows that Marx's critiques coincided with those made by the Romantic critics of capitalism ("feudal socialists," in the language of the Manifesto) on at least on one point, namely their horror at the imposition of commercial relations as the only form of human interaction. However, the similarity obviously ended there; for while the Romantic "feudal socialists" advocated a return to patriarchal relations in terms that, despite the "incisiveness" of their critique, were "half lamentation, half lampoon; half echo of the past, half menace of the future" (Marx \& 
Engels, 1848: 30), Marx and Engels aspired to emancipation and predicted that it would come in the future.

Thus, we can understand why Hirschman, in his discussion of the rival interpretations of the market society (Hirschman, 1982), included Marx and the Romantic critics of capitalism in the same category, namely "self-destruction theses," which covers all perspectives that hold that "capitalist society [...] exhibits a pronounced proclivity toward undermining the moral foundations on which any society, including the capitalist variety, must rest." (Hirschman, 1982: 1466). However, as noted by Hirschman, Marx limited himself to highlighting the corrosion of traditional values in bourgeois society, never developing his reasoning along the lines of an implosion of capitalism as a result of the liquefaction of its moral foundations. For Hirschman, the paradigmatic cases of the "self-destruction thesis" were Schumpeter, Horkheimer and Hirsch. Today, 25 years later, Hirschman might possibly have considered including Bauman in the same category.

\subsection{The two phases of the great transformation}

Given liquidity's long lineage as a metaphor for the market society, it is surprising that it now appears in Bauman associated only to the "present stage of the modern era" (Bauman, 2000: 2).

Recognising that the "melting of solids" is a permanent feature of modernity, Bauman argues that the "great transformation" must have occurred in two phases. In the first, the "solids" were the patterns of pre-modern dependence and interaction; these solids were broken, but immediately replaced by others that were as hard as the previous ones individuals were torn from their traditional relationships of dependency and belonging, but immediately thrust into "frames which [...] encapsulated the totality of life conditions and life prospects and determined the range of realistic life projects and life strategies" (Bauman, 2000: 7), i.e. social classes, sexual difference or the Fordist factory. In the second phase (i.e. today), these new "solids" are being liquefied, as the patterns of dependence and interaction become malleable to a point that could never have been experienced or even imagined by past generations, and without anything tangible or lasting arising to replace them:

These days, patterns and configurations are no longer 'given', let alone 'self-evident'; there are just too many of them, clashing with one another and contradicting each other's 
commandments, so that each one has been stripped of a good deal of compelling, coercively constraining powers. (Bauman, 2000: 7)

Let us look in a little more detail at each of the phases of the great transformation, as presented in condensed form in Bauman (2001). At the beginning, modernity appeared in the form of freedom - and the beginning, in Bauman's history of modernity, was when God appeared to man in the Renaissance, in this case to Pico della Mirandola, announcing that, unlike the other creatures that "have a defined nature prescribed by me, you may determine your own limits according to your own will" (Bauman, 2001: 21). This was the emancipatory face of modernity.

The "constitutive act of modern capitalism," as Bauman recalls, involved breaking with the old economy based upon the production of use value to satisfy domestic or community needs, uprooting both businesses and labour in the process: "That double act set the actions of profit-making, as well as making one's livelihood, free from the web of moral and emotional, family and neighbourly bonds - but by the same token, it also emptied such actions of all the meanings it used to carry before" (Bauman, 2001: 29). For the entrepreneur, "the separation of business from the household was a genuine emancipation. His hands had been unbound, the sky was the sole limit beyond which his ambition did not dare reach" (Bauman, 2001: 30). But for the workers, uprooted from their communities of origin and thrust onto the factory floor, the separation transformed labour from a purposeful activity into mere drudgery devoid of any kind of dignity. For the craftsmen and peasants of yesterday,

[...] it was no longer clear [...] what 'work well done' would mean. [...] Following the soulless routine of the factory floor, watched by no kinsman or neighbour but solely by the constantly suspicious and rat-smelling foreman, going through machine-dictated motions with no chance to admire the product of one's exertions, let alone to sit in judgement on its quality, rendered the effort all but 'futile'. (Bauman, 2001: 29)

And, as human beings resisted the futility of effort, and this resistance was interpreted as laziness - the aversion to work that appears in economics textbooks - work could only be obtained by coercion, combined with convenient doses of moralist exhortation designed to induce consent. The dual movement of separation thus revealed the other face of modernity: "The modern - capitalist - arrangement of human cohabitation was Janus-faced; one face was emancipatory, the other coercive, each being turned towards a different 
section of society" (Bauman, 2001: 26). In the first phase of the "great transformation," Bauman (2001: 30) concludes, "modern capitalism [...] 'melted all solids'; [...] but the melting job was not an end in itself: solids were liquefied so that new solids, more solid than the melted ones, could be cast."

But modernity, at the same time that it bound subordinates to the factory floor where they could be easily supervised, also obliged the supervisors to remain in their watch towers, thus creating a situation of mutual dependence. United in the Panopticon, for better or for worse, its inhabitants knew that this was both a theatre of conflict and a negotiating table. Management, in this framework, was an exercise that oscillated between the coercive imposition of routines and attempts to recreate in vitro a new "sense of community." The Fordist factory, writes Bauman (2001: 37), which "attempted to synthesize both tendencies," was paradigmatic of another facet of this phase of modernity: the idea that order in production and society had to be managed.

The second stage of the "great transformation" began, according to Bauman in terms borrowed from Marx, the moment the owner of the instruments discovered that he was not obliged to conduct the orchestra: "As soon as they could afford it, capitalist entrepreneurs shifted managerial chores to hired servants" (Bauman, 2001: 39).

But this was only an intermediate stage, corresponding to an episodic "managerial capitalism." The moment when managers would repeat the act of disengagement was soon to arrive, inaugurating "times of high speed and high acceleration, shrinking terms of commitment, of 'flexibility', 'downsizing' and 'outsourcing', times when people stayed together only 'until further notice' and as long (never longer) 'as the satisfaction lasts'" (Bauman, 2001: 41). In short, this was liquid modernity.

In post-panoptic modernity - liquid modernity - the art of escape has become the principal technique for consolidating power. Deregulation is sought because the powerful do not want to be regulated - "for power to be free to flow, the world must be free of fences, barriers, fortified borders and checkpoints" (Bauman, 2000: 14) - but also because they no longer need to regulate anyone. Now, obedience is obtained by the simple threat of disengagement or exit: "Amidst uncertainty and insecurity, discipline (or rather, submission to the 'there is no alternative' condition) is self-propelling and self-reproducing" (Bauman, 2001: 42), making those obedience factories, the expensive panopticons, superfluous. 
The dismantling of the panopticons is experienced by individuals (and even by Bauman) with some perplexity. On the one hand, the panopticon regime was cruel and inhuman, and in this sense, its disappearance may be considered a form of liberation. But, on the other, it had "some advantages for the victims - it brought them benefits which were hardly noticed at the time and have only recently become salient through their disappearance" (Bauman, 2001: 42): it provided them with "a trustworthy frame" in which they could "confidently inscribe their hopes and dreams of a better future," and it gave meaning to their struggle for better living conditions.

\subsection{Individualization in liquid modernity}

The form taken by modernity at present - liquid modernity - is distinguished from the previous one, according to Bauman (2000: 29), not only by the collapse of the belief in an "attainable telos of historical change [...], some sort of good society, just society and conflictfree society," but also by "the deregulation and privatization of the modernizing tasks and duties," i.e. by a change in the meaning of individualization.

In liquid modernity, individualization is no longer conceived as emancipation from the bonds of communal dependence. In the absence of any clear and reliable normative framework, identity is no longer a "given," but instead has been transformed into a "task" for which actors (now authors) are responsible: "Modernity replaces the heteronomic determination of social standing with compulsory and obligatory self-determination" (Bauman, 2000: 32).

However, the tasks involved in identity construction are not carried out by everyone on an equal footing. While for some (a few), the two poles of individualization - freedom and security - are mutually reinforced (freedom of movement is a guarantee of power and safety), for others (the majority), freedom is offered only in exchange for security and experienced as "a kind of uncertainty, of dark premonitions and fear of the future" (Bauman, 2001: 48). All are warned that the prospects of survival, improvement and dignity depend exclusively upon oneself, and that everyone is personally responsible in the event of failure. But, as only some possess the necessary resources to acquire security through freedom, liquid modernity operates, in reality, by unequal distribution of the risks. For the majority, de jure autonomy does not translate into de facto autonomy; or in other words, the increase in negative freedom does not correspond to an increase in positive freedom. 
Irrespective of individual circumstances, the private construction of identity is always a task to be carried out within a context of uncertainty. When the "codes and rules" are not "self-evident," no longer prescribing clearly defined obligations (Bauman, 2000: 7), when "the status of all norms [...] has [...] been severely shaken and become fragile" (Bauman, 2000: 79), the construction of identity tends to be transformed into "a perpetual agony of indecision" (Bauman, 2000: 20), as a result of uncertainty as to the definition of one's own purposes and as to the actions and intentions of others.

\subsection{Uncertainty, liquidity and their manifestations}

In an atmosphere of uncertainty, in a "world devoid of stable and trustworthy meaning," liquidity - that is, the "substitution of the techniques of escape and elision for engagement and mutual commitment" (Bauman, 2000: 108, 109) - appears as a rational response on the part of individuals: "Rational choice' in the era of instantaneity means to pursue gratification while avoiding the consequences, and particularly the responsibilities that those consequences imply" (Bauman, 2000: 128).

Liquidity is manifested as a loss of the meaning of personal commitment, or commitment with a "life plan." The world "in which the future is at best dim and misty, but, more likely, full of risks and dangers" (Bauman, 2000: 163) makes the establishment of long-term goals unattractive. Liquidity thus involves a modification of time - the loss of long-term meaning with its break-up into a sequence of moments. For those for whom "domination consists in one's own capacity to escape, to disengage, to "be elsewhere'" (Bauman, 2000: 120), instantaneity becomes an ideal of reference. Bill Gates, according to Sennett's observations, mentioned by Bauman, makes success depend upon "positioning oneself within a network of possibilities rather than paralyzing oneself in one particular job." This implies avoiding lasting attachments or commitments:

He was cautious not to develop attachments (particularly a sentimental attachment) or lasting commitment to anything including his own creations. [Bill Gates] was not afraid of taking a wrong turn, since no turn would keep him going in one direction for long, and since turning back or aside remained constantly available options. (Bauman, 2000: 124)

For capital able to "travel fast and travel light" (Bauman, 2000: 121) the compression of time is a source of freedom and security. For others, it is only freedom, or rather, the freedom to choose consumer commodities. For these, the activity of consuming is the 
privileged form of "escape from the agony called insecurity" (Bauman, 2000: 81). The objects displayed on supermarket shelves are thus the only things that seem "complete with the promise of certainty" of immediate satisfaction (Bauman, 2000: 81). The life of the consumer is a sequence of moments of gratification.

Liquidity also involves an alteration in the meaning of interpersonal commitments. A world in which the future is unclear makes it unadvisable to surrender "private interest in order to increase group power" (Bauman, 2000: 163): "[H]olding too fast, burdening one's bond with mutually binding commitments, may prove positively harmful and the new chances crop up elsewhere" (Bauman, 2000: 13).

Those for whom freedom and security are served in a packet easily dispense with commitment - their safety presupposes flexibility. Others may desire stability or miss it. But, as the offer of security is scarce, the best alternative consists in always seeking to imitate the former. The consequence is

[...] the fading and wilting, decomposing and falling apart of human bonds, of communities and of partnerships. Commitments of the 'till death do us part' type become contracts 'until satisfaction lasts', temporal and transient by definition, by intention and by pragmatic impact and, therefore, with the tendency to be unilaterally broken when one of the parties senses more opportunities and more value in abandoning the partnership than in the attempt to save it at whatever incalculable cost. (Bauman, 2000: 163)

In the process, what is changed is the meaning of interpersonal relationships: "bonds and partnerships tend to be treated as things meant to be consumed, not produced; they are subject to the same criteria of evaluation as all other objects of consumption" (Bauman, 2000: 163).

\subsection{Social construction and the instability of identity}

Contrary to what might be imagined, the construction of identity in liquid modernity has not stopped being a social process. What has changed are the mechanisms in that process. In the absence of the invisible Big Brother of the first modernity, able to stipulate absolute values and prescribe objectives that had to be pursued, the question of values has also been privatized and transferred to individuals. The uncertainty of means is now joined by a new type of uncertainty - an uncertainty of ends, which consists in determining, "in the face of all the risks known or merely guessed, which of the many floating seductive ends 'within reach' [...] offer priority" (Bauman, 2000: 61). 
Individuals, although separate, do not decide upon ends with their backs turned to one another. They observe each other attentively and anxiously, in the expectation of finding not only proof that they are not the only ones experiencing the agony of uncertainty, but also "examples" - signs of ends that are worth pursuing. The others, on the other hand, offer themselves up as objects of consumption in "a scene on which private dramas are staged, put on public display and publicly watched" (Bauman, 2000: 70) or as "counsellors" in a market of examples.

To be an object of "desire and admiration" (Bauman, 2000: 67) is the condition for a counsellor's success and authority in the market of examples, and proof of the importance of the values that s/he promotes. However, the causal bond between the will to follow an example and the authority of the exemplary person is not clear: "Authority expands the ranks of the followers, but, in the world of uncertain and chronically underdetermined ends, it is the number of the followers that makes - that is - the authority" (Bauman, 2000: 67).

The value of the examples is necessarily precarious: "Examples and recipes remain attractive as long as they remain untested" (Bauman, 2000: 72). As there is no example capable of fulfilling its promises of lasting satisfaction, the recipes for a "good life" tend to become obsolete even before they reach their sell-by date. For individuals, the attempt to reduce the uncertainty of ends by observing examples tends to turn consumption into an addiction, and like all addictions, it "destroy[s] the possibility of being ever satisfied" (Bauman, 2000: 72) - the more it is practised and the more frustrations it originates, the more necessary it becomes, generating even more frustrations. In society, the value of examples is ephemeral - examples pass from fame to oblivion unpredictably or uncontrollably, like the winds or tides.

\subsection{The commodification of commitment and the instability of interpersonal relations}

The change in the meaning of interpersonal commitment arising from the commodification of social bonds, that is, from their subjection to the cash nexus, consequently removes all responsibility for the fate of relationships. When the relationship is conceived as an acquisition on the market, its continuity becomes conditioned only by the test of satisfaction. Trying to contribute actively to maintain it, with sacrifice if necessary, makes about as much sense as making an effort to like a product that does not live up to one's expectations. In a disappointing relationship, as in the case of a disappointing product, the 
natural thing to do, whenever possible, is to exchange it for something else. Consequently, the precariousness of relations tends to turn into a self-fulfilling prophecy:

If the human bond, like all other consumer objects, is not worked out through protracted effort and occasional sacrifice, but something which one expects to bring satisfaction right away, instantaneously, at the moment of purchase - and something that one rejects if it does not satisfy [...] - then there is not much point in 'throwing good money after bad', in trying hard and harder still, let alone in suffering discomfort and unease in order to save the partnership. (Bauman, 2000: 164)

\subsection{Uncertainty, liquidity and insecurity}

Uncertainty, which for most people is experienced as insecurity and anxiety, leading as a rational response to the search for liquidity, tends to produce increased systemic instability and insecurity. Of the consequences involved in this tendency, Bauman highlights social fragmentation.

Liquid modernity is a time of "secession" in which those most skilled at the art of evasion manage to detach themselves from their commitments and responsibilities. But, as this "secession" brings together fugitives from other similar situations, the process gives rise to "bubbles", sheltered spaces that are communities only in name, sealed from the outside and united only by the perception of an external threat. The result is "ghettoization" - a process of "spatial confinement and social enclosure" (Bauman, 2001: 117), which is self-fulfilling.

Channelling the emotions generated by existential uncertainty into a frantic search for 'safetyin-community' acts as all other self-fulfilling prophecies do: once embarked on, it tends to substantiate its original motives and produce ever new 'good reasons' and justifications for the original move. (Bauman, 2001: 118)

When the outside appears increasingly threatening, the "voluntary ghettos," which are entered on the belief that it is always possible to leave, gradually become more and more like real ghettos. The fragmented society may then become something truly dangerous - a fertile ground for the expansion of the market of law and order.

But the fragmented society which, according to Bauman, will result from liquefaction, is also a society that dissolves the "forces that could keep the questions of order and system on the political agenda" and the "bonds which interlock individual choices in collective projects and actions" (Bauman, 2000: 6): 
The kind of uncertainty, of dark premonitions and fears that haunt men and women in the fluid, perpetually changing social environment in which the rules of the game change in the middle of the game without warning or legible pattern, does not unite sufferers: it splits them. The pains it causes to the individuals do not add up, do not accumulate or condense into a kind of 'common cause' which could be pursued more effectively by joining forces and acting in unison. (Bauman, 2001: 48)

Bauman's liquidity is a cumulative process. It is a trap, a dystopia capable of replacing the nightmares of Orwell and Huxley.

\section{Keynes's liquidity}

Keynes's liquidity has its origins in the separation of property and control, and is, simultaneously, a condition of that separation, occurring for the first time, as in Bauman, at the moment when the owner of the orchestra discovers that he does not necessarily have to conduct it.

There was a time, Keynes recalls at the beginning of his famous Chapter 12 of the General Theory, in which enterprises "were mainly owned by those who undertook them or by their friends and associates" and "investment depended on a sufficient supply of individuals of sanguine temperament and constructive impulses who embarked upon business as a way of life" (Keynes, 1936: 150). In these cases, investment decisions were irrevocable, "indissoluble, like marriage" (Keynes, 1936: 160). At that time, "productive" investment was solid (or fixed).

With the creation or development of organised "investment markets," this era came to an end. Characterised by liquidity, "investment markets" undertake a daily reassessment of investment - something which did not make sense in the previous context, characterised by the indissolubility of the bonds of the investor with his assets - and as they reassess, they give the individual the opportunity "to revise his commitments" (Keynes, 1936: 151), i.e. to get rid of his assets in order to acquire - or not - others offered on the market. These markets seem to be a fantastic institutional innovation which brings together the best of both worlds: the income that treasures cannot promise and the liquidity that was believed to be an attribute of treasures. 


\subsection{The ambiguity of liquidity}

However, for Keynes, liquidity was ambiguous, involving what he himself considered to be a dilemma: it "often facilitates, though it sometimes impedes, the course of new investment" (Keynes, 1936: 160).

The reason why liquidity may facilitate investment becomes clear from the moment we understand the "extreme precariousness of the basis of knowledge on which our estimates of prospective yield have to be made" (Keynes, 1936: 149). In a context of uncertainty, liquidity is the emergency exit that the investor needs to know exists, before daring to enter a poorly-lit tunnel whose end is out of sight. It is the escape route, in the event of an emergency: "For the fact that each individual investor flatters himself that his commitment is 'liquid' [...] calms his nerves and makes him much more willing to run a risk" (Keynes, 1936: 149).

It is clear, however, as Keynes reminds us, that investment decisions are revocable for the individual, but not for the community - there is an absence of micro-macro correspondence that can translate into a reduction of individual risk which is not transposable to the collective.

More complex is the reason why liquidity may impede the course of new investment. "Investment markets" were set up on the assumption that they would facilitate the miracle of the invisible hand and ensure that capital was applied to more socially advantageous uses. According to Keynes, things in fact happen the other way around. Let us imagine, however absurd it may seem, that an omniscient trader considers it advantageous to invest a large sum of money in setting up a new company. Would he be prepared to go ahead with this if there were a cheaper equivalent deal available on the "investment market"? In that case, the new investment would be abandoned in exchange for the acquisition of shares in an already-existing business; his assessment of the (liquid) market would have impeded the new investment. But why would the market assess the investment below its fundamental value - that is, the value that only the omniscient agent knows?

The market can be "mistaken"; indeed it tends to make mistakes systematically, because there are no omniscient agents, or at least, no agents that are considered omniscient by the others, and because individual choices made in a context of uncertainty are not independent. 
The value of assets is conventional in nature; that is, it results from a multiplicity of decentralised, but not independent, decisions. The awareness that the value of assets results from a multiplicity of decisions justifies each individual taking account of others' choices when making his own decisions. In fact, his gains and losses depend upon his capacity to predict the choices made by the others. And, to the extent that the decisions of each of those others are also conditioned by expectations of the same type, it is a question of guessing what others think others will do. In the "investment markets," as Keynes wrote, it is not only a question of predicting which assets are going to go up, or which the others think are going to go up; rather, there is a third degree of recursivity involved, namely "anticipating what average opinion expects the average opinion to be." Indeed, there may even be those that "practise the fourth, fifth and higher degrees" of recursivity (Keynes, 1936: 156).

Keynes terms this activity of second-, third- or higher-degree prediction speculation, which he considers a form of game-playing, contrasting it with enterprise, i.e. "the activity of forecasting the prospective yield of assets over their whole life" (Keynes, 1936: 158) - which is known today as the fundamental value of assets. In the world of financial liquidity, speculation may be considered as a kind of rational behaviour - if rationality is redefined (Orléan, 1999; Rodrigues, 2007). Speculation, Keynes writes (1936: 155),

[...] is not the outcome of a wrong-headed propensity. It is the inevitable result of an investment market organised along the lines described. For it is not sensible to pay 25 for an investment of which you believe the prospective yield to justify a value of 30 , if you also believe that the market will value it at 20 three months hence.

In this market, it would be irrational to base one's investment decisions on the knowledge that is available about the profitability of an asset:

Investment based on genuine long-term expectation is so difficult today as to be scarcely practicable. He who attempts it must surely lead much more laborious days and run greater risks that he who tries to guess better than the crowd how the crowd will behave. (Keynes, 1936: 157)

\subsection{Self-referentiality of speculation and instability}

Today we understand, better than in Keynes' day, that systems like the financial markets may behave in a complex, even chaotic, fashion. In these markets, as Orléan (1999: 59) explains, "market opinion is at the same time the object that each person is trying to predict, 
and the product - what emerges from the individual opinions when each of those individuals is trying to discover the majority opinion."

Referring to this dynamics as self-referential, Orléan shows that, in certain circumstances, self-referential groups "manage to stabilise through the endogenous production of a belief recognised by all" (Orléan, 1999: 60) - a convention - and shows at the same time that these conventions may enter into collapse when under attack by speculators seeking advantages by "playing" against them.

\subsection{The liquidity trap and the need for heteronomic regulation}

Liquidity, which, in the financial markets, seems to be a rational response to uncertainty, tends to give rise to systemic instability, increasing the individual's uncertainty. In this context, what appeared extraordinary to Keynes was that, despite everything, there was still room for enterprise. If enterprise had rational grounds, if it depended upon simple calculation - on the "weighted average of quantitative benefits multiplied by quantitative probabilities" - it would long ago have "faded and died" (Keynes, 1936: 161-162). If it still exists, it is because it depends more on spontaneous optimism or animal spirits - "a spontaneous urge to action" - rather than on the outcome of a mathematical calculation.

But as that spontaneous optimism that enables people to act despite uncertainty is, like any psychological state, inconstant, the "economic life of the modern world" will necessarily be afflicted by "crises of confidence" (Keynes, 1936: 161). In contexts of crises of confidence, when fear paralyses those animal spirits, torn between consumption, investment and liquidity, agents tend to choose the most liquid of assets - money.

We can now formulate Keynes's dilemma in another way: the markets contain panic, in both senses of the word "contain" (Dupuis, 1992). Liquidity "calms the nerves" and encourages the formation of capital, while at the same time generating instability and "crises of confidence," which result in a disorderly race for the emergency exit.

For Keynes, as we know, laissez faire would not survive commotions of these proportions. For him, order and the reproduction of the market society depended upon a centre of rationality that is outside it: "I expect to see the State, which is in a position to calculate the marginal efficiency of capital-goods on long views and on the basis of the general social advantage, taking an ever greater responsibility for directly organising investment" (Keynes, 1936: 164). 


\section{The mechanisms of liquidity}

This comparative reading of Bauman and Keynes suggests, as I have already mentioned, the existence of transversal liquidity mechanisms that cut across different institutional domains. Consideration of this hypothesis involves a generalization of different key concepts, present in both authors' approach to the question of liquidity. These are: uncertainty, expectations, rationality, irrationality, enterprise, speculation, conventions, norms, instability of conventions and the liquidity trap. In this section, I will discuss these concepts in pairs.

\subsection{Uncertainty and expectations}

Uncertainty, conceived broadly and informally as a mental state of doubt about the best course of action to take (Beckert, 1996) - a situation in which the actor simply does not know what to do - is obviously a common state in life, even if it is more pronounced in some cases than in others.

This applies to the Keynesian type of uncertainty. This type of uncertainty, which is manifested in a particularly acute form in the monetary and financial markets, may be present in all situations in which the consequences of actions are projected into a long-term future, without there being any knowledge base that enables probabilistic expectations to be formulated.

But Keynesian uncertainty (uncertainty as to the best means of achieving clear ends, resulting from a lack of knowledge - the epistemic uncertainty of means) is not the only form of uncertainty, nor the only relevant form. Bauman speaks of an uncertainty of ends, an axiological uncertainty, which refers to the mental state of doubt about what ends should be pursued. He also suggests a third type of uncertainty - a deontic uncertainty, concerning duties and obligations - which involves doubt as to the individual's relationship with norms.

Recognition of these three types of uncertainty naturally involves ontology of the actor that is not that of economic orthodoxy. It presupposes an actor that recognises the norms as such, that is, as rules that prescribe obligations, the compulsoriness of which is not solely determined by a judgement based on a cost-benefit computation. It also presupposes an actor who is able to reflect upon his/her own preferences and to choose what ends to pursue - an actor that is autonomous, though limitedly so, in the sense that, in forming his 
beliefs, he depends not only upon himself but also upon others (both in the process of socialization and in the situational context).

Action in a context of uncertainty is always based upon expectations which, like forms of uncertainty, may be epistemic, axiological and deontic. The transversal mechanisms of liquidity involve these three types of uncertainty and expectations.

\subsection{Rationality and irrationality}

The recognition of non-probabilistic uncertainty leads to a reconceptualization of rationality. Keynes's agent does not simply have the cognitive resources that enable him to choose rationally (in the terms prescribed by the rational decision theory). He can only be rational if rationality is conceived in the broader sense of justified choice. The relevant rationality in the framework of transversal liquidity mechanisms refers to deliberation processes that operate in parallel upon ends (subject to reconfiguration) and (given and discovered) means.

What is irrational in this perspective is the unsuitability of means to ends - the choice of ends that cannot be achieved with the means available, or of means that do not lead to the chosen end.

\subsection{Enterprise and speculation}

In Keynes's terms, the entrepreneur is the investor who "direct[s] his mind to the long-term prospects and to those only" (Keynes, 1936: 160), basing his decisions upon estimations of the fundamental value of assets. Enterprise can be generalized and integrated into the transversal liquidity mechanisms as an attitude of commitment to a life project or interpersonal relationship. Commitment involves responsibility - the awareness that the fate of the project or the relationship depends, at least in part, on a personal contribution and on a disposition to contribute, which is translated into practice - as well as a belief in the fundamental value of the project or relationship, that is, in its intrinsic non-conventional value.

Liquidity is a state of non-commitment in what concerns both life plans and relations with others. Preference for liquidity is a rational response to uncertainty, any type of uncertainty, which, when generalized, tends to cause enterprise to be replaced with speculation.

Speculation, which in the financial markets consists of predicting the conventional value of assets, when generalized becomes the selection of ends guided by authoritative "examples," as mentioned by Bauman, or the conditioning of normative obligations to the 
anticipated degree of compliance shown by others with those same obligations. Speculation, therefore, involves deliberation and action that are oriented by conventional assessments.

\subsection{Conventions and norms}

The conventions that for Keynes are procedures for the formation of expectations, and the expectations on the value of assets themselves, may be generalized as intersubjective beliefs that emerge from the interaction between agents. They are not based upon any fundamental value external to the self-referential game of beliefs, a situation that is subjectively acknowledged. In contrast, norms are intersubjective beliefs that are rooted in fundamental values and are recognised as such by agents; thus, they may motivate action irrespective of any cost-benefit analysis.

The fact that norms refer to fundamental values is no guarantee that agents will automatically adhere to them (that is why sanctions exist when there is failure to comply), since, in relation to norms, there is always room for the justification of non-compliance, as a consequence of conflict with other norms, interpretation and expectations as to compliance by others. The last aspect is particularly important in the sense that it suggests that norms are also subject to self-referential processes with an impact on deontic expectations, although the external nature of the fundamental value relative to the self-referential game may provide greater stability.

On the other hand, the fact that conventions are not rooted in fundamental values does not exclude the possibility that they may constitute grounds for stable beliefs and expectations. Some conventions acquire such a degree of stability that they endure even when there are strong reasons for being abandoned.

\subsection{Instability of conventions}

At the limit, Bauman's liquid modernity, like Keynes's financial markets, involves social systems devoid of fundamental values - not because those values do not exist, but precisely because they are in conflict with one another. Order in these systems is based on conventions. Keynes and his successors have described the self-referential dynamics of conventions in the financial markets. Bauman's specular game with respect to axiological uncertainty illustrates this well in the domain of ends. Something similar may occur with obligations. Since the normative disposition of the agent with limited autonomy is conditioned by the expectation that others will comply (i.e. it involves the expectation of 
reciprocity [Gintis et al, 2005]), his/her deontic expectations are also subject to the now familiar self-referential process: my disposition depends upon the disposition of others, whose disposition in turns depends upon...

Conventions are arbitrary - they are not based upon any fundamental value. But if they remained stable, despite being arbitrary, as in some of the equilibrium outcomes achieved by Schelling's "critical mass models" (1978), there would be no rational grounds for desiring liquidity. Agents would formulate their expectations on the basis of conventions that would become self-fulfilling prophecies.

Liquidity is sought because it is not possible to trust the stability of conventions. If in some circumstances conventions are stable, as pointed out above, the fundamental question is to understand the reasons why they might not be so.

Conventions are stable when most agents have no reason to abandon them, or if, despite there being good reasons to do so, this will bring unbearable costs for an agent acting in isolation (Runde, 1991). In a country where cars drive on the left, there might be advantages to driving on the right in a traffic jam; however, the risks inherent in that choice are sufficient to deter most drivers. Even in the financial markets, it is possible to find examples. Keynes suggests one: as disapproval is most likely when one errs against a convention than when one errs with it, wage-earners will tend to follow the convention even when they have reasons to believe that they will lose out by doing so.

When there are good reasons to abandon the convention, and when this does not involve prohibitive costs, there is the potential for the convention to become unstable. Amongst the various good reasons we could count: the convention's deviation from that which the actor takes as a fundamental value; incentives arising from opportunities to gain in counterconventional "gambles," as occurs with large speculators on the stock exchange; or the disclosure of new information.

The last aspect, underlined by Keynes, is particularly important. In the world of noncommitment, the mind is focused on everything except on that whose advantages may only be realised in the long term; it tends, particularly, to concentrate upon current facts, whose importance may result not from the relevance of the facts themselves, but from the importance that is believed to be attributed to them by others. In this way, completely irrelevant events may break a convention. There are abundant examples in the financial markets. There are also a great many examples in the domain of ends and obligations: media 
coverage of an example may be enough to cause crowds to change direction, just as the publication of a notable case of tax evasion may provide "justification" for millions of others to do the same (Gintis et al, 2005).

\subsection{The liquidity trap}

Conventional orders are by nature unstable and are constantly at risk of collapse. The liquidity trap represents that collapse in Keynes - once trust is lost in conventions, agents take refuge in the most liquid of assets. To put it in general terms, the liquidity trap corresponds to the rupture of all commitments, whatever form those might take, to mass divestment and panic.

In Bauman, the panic resulting from the loss of confidence takes two forms: The first is the non-aggregation of individual suffering in common causes; the second, escape - seeking refuge inside protected "bubbles." Bauman's two forms have in common the refusal to "invest" in social relations or to enter into commitments and obligations of any kind.

The first kind of trap leads Bauman to the representation of liquid modernity as a society devoid of means that enable it to act upon the systemic origin of individual suffering - a blocked society.

Collective action, as the abundant theoretical and empirical research into the subject has shown (Ostrom, 1990, Gintis et al., 2005), depends crucially upon prospects of indefinite continuation of interactions, being therefore incompatible with the precarious relations characteristic of liquid modernity. Bauman is particularly concerned with the impossibility of collective action in the political sphere. However, there are other domains, including those that most concern economists, in which this implication of liquidity is manifested.

In modern companies and organizations, cooperation has always been a prerequisite for production as important as the division of labour, monitoring and coercion. Companies and organizations have always claimed not only the bodies but also the souls of their employees. But, while "solid" modernity trusted more in the control of the body than the soul, postpanoptic modernity requires both in equal proportion. This is clear in the development of the "management sciences," which are no longer simply a form of social engineering, but have become a way of engineering minds, involving pathetic identification rituals such as those that are now frequently staged by companies and other organizations. 
But, in conditions of liquid modernity, loyalty - friction on exit in Hirschman (1970) - is more difficult to cultivate: concentrating on the art of escape, residents are more concerned with the acquisition of skills and with the realisation of deeds that can facilitate their exit, or which make the threat of exit more credible, than with the realisation of tasks that could contribute to the continuation of the collective undertaking. In post-panoptic companies and organizations, just as in the political sphere, liquidity may dissolve the grounds for collective action.

Bauman's second kind of trap is the panicky flight towards the walled refuge of the home or "community," a flight through emergency exits that is not disorderly, in the sense that each person races to the door that seems to be chosen by those who are similar to him/her, just to find him/herself on the other side amongst a group of likeminded souls, united in their fear of the outside, but in all other respects as separate as before. As the result, albeit unintentional, of this movement is segregation (Schelling, 1978), the fractured society that results from this collective exit is even more dangerous than that which justified the flight. Bauman illustrates this process with the case of closed condominiums and other segregated residential areas in cities of liquid modernity. However, something similar may occur with the fragmentation of public health and education services as a consequence of the exit of the middle and upper classes.

It is difficult to conceive human cohabitation in a merely conventional order, since contracts (the institutional instrument presented as the cement of liquid modernity) depend much more than we suppose upon a cluster of institutionalised normative values and obligations. As all contracts are incomplete, although to varying degrees, the viability of contractual bonds always depends upon the non-contractual element that they necessarily involve - the normative obligation to respect one's promises. The grounds for normative obligation, as is well known, may be prudence or honesty. The problem is that liquidity does not appear to foster either of these virtues, as both prudence and honesty presuppose stable and continuous relational contexts.

The effectiveness of the contract depends upon "something" more than its specification, monitorization and the threat of sanctions. Arrow called that thing trust. The problem is that trust, as Arrow reminds us, is an asset that money cannot buy: "if we have to buy it, you already have some doubts about what you have bought " (Arrow, 1974. 23). 


\section{Concluding notes}

In the light of this analysis, liquid modernity (i.e. society devoid of normative references and shared values, a merely conventional order) appears impossible, an unrealizable utopia - or dystopia. The art of escape, when practised by everyone at the same time, destroys itself, becoming a trap - generalised flight which hampers the establishment of any long-lasting commitments or ties, including those that liquid modernity itself, based on contracts, presupposes. But, to the extent that attempts to realise the utopia of liquidity can, and manifestly do, exist, it is worth trying to predict some of the possible futures that might result from it.

Bauman's analysis, like Polanyi's (1944), suggests that movement towards liquefaction (or the realization of the market society) necessarily unleashes a counter-movement. That counter-movement, however, is politically indeterminate - it may give rise to different scenarios. Bauman indicates two possible scenarios, distinct but interrelated, and a contrasting counter-scenario. The first, inspired by Erich Fromm, foresees that

[...] when "each individual must go ahead and try his luck," when "he had to swim or sink" "the compulsive quest for certainty" takes off, the desperate search for "solutions" able to "eliminate the awareness of doubt" begins - anything is welcome that promises to "assume the responsibility for 'certainty'." (Bauman, 2000: 20)

To the extent that governments, "impotent to strike at the roots of the existential insecurity and anxiety of their subjects" (Bauman, 2000: 109), may feel tempted to provide security (although in the form of derivative products, oriented towards safeguarding the body and property), the "compulsive quest for certainty" may degenerate into paroxysms of security.

Bauman's second scenario, the flight to the community, leads to ghettoization. Complemented by an emptying of the functions of sovereignty to the point that the State loses its monopoly on coercion, this would lead to a transfer of State violence to the neotribal violence of communities.

Refusing to admit the possibility of any community reinsertion, Bauman rests his hopes on a counter-scenario in which social order is constructed "by confrontation, debate, negotiation and compromise between values, preferences and chosen ways of life and selfidentifications of many and different, but always self-determining, members of the polis" (Bauman, 2000: 178). What he is proposing is the "republican model of unity," the only one he considers compatible with "the conditions of liquid modernity." 
The problem is how to make this same modernity which led to the "corrosion and slow disintegration of citizenship" (Bauman, 2000: 36) evolve in the direction of unity in difference. We don't know how, nor whether, it is possible. Like Bauman, we can only warn and hope that the diagnosis, by unveiling the lost nexus between objective conditions and subjective experiences, will help "disclosing the possibility of living together differently" (Bauman, 2000: 215) and arouse the will to succeed.

Translated by Karen Bennett

Revised by Teresa Tavares

\section{References}

Arrow, Kenneth (1974), The Limits of Organizations. New York: Norton.

Bauman, Zygmunt (2000), Liquid Modernity. Cambridge: Polity Press.

Bauman, Zygmunt (2001), Community: Seeking Safety in an Insecure World. Cambridge: Polity Press.

Beckert, Jens (1996), "What is Sociological about Economic Sociology? Uncertainty and the Embeddedness of Economic Action," Theory and Society, 25, 803-840.

Dupuis, Jean-Pierre (1992), Le sacrifice et l'envie: Le liberalisme aux prises avec la justice sociale. Paris: Calman-Lévi.

Gintis, Herbert et al. (orgs.) (2005), Moral Sentiments and Material Interests: The Foundations of Cooperation in Economic Life. Cambridge MA: The MIT Press.

Hirschman, Albert (1970), Exit, Voice and Loyalty: Responses to Decline in Firms, Organizations, and States. Cambridge, MA: Harvard UP.

Hirschman, Albert (1982), "Rival Interpretations of Market Society: Civilizing, Destructive, or Feeble?" Journal of Economic Literature, 20, 1463-1484.

Keynes, John M. (1936), The General Theory of Employment, Interest and Money. London: Macmillan.

Marx, Karl; Engels, Friedrich (1848), Manifesto of the Communist Party, in Lewis S. Feuer (ed.), Marx and Engels: Basic Writings on Politics and Philosophy. Garden City, NY: Anchor Books/Doubleday [1959].

Ostrom, Elinor (1990), Governing the Commons: The Evolution of Institutions for Collective Action. Cambridge: Cambridge UP.

Orléan, André (1999), Le pouvoir de la finance. Paris: Odile Jacob.

Polanyi, Karl (1944), The Great Transformation: The Political and Economic Origins of Our Time. Boston: Beacon Press.

Rodrigues, João (2007), "Liquidez, especulação e convenções - Uma análise a partir de Keynes," mimeo. 
Runde, Jochen (1991), "Keynesian Uncertainty and the Instability of Beliefs," Review of Political Economy, 3(2), 125-145.

Schelling, Thomas C. (1978), Micromotives and Macrobehavior. New York: Norton and Company. 